\title{
Tek Bir Seansta Zirve Oksijen Kullanım Düzeyini Veren En Yüksek Güç Çıktısını Tahmin Etmenin Basit Bir Yöntemi
}

\section{A Simple Method to Predict the Highest Power Output to Elicit Peak Oxygen Consumption in a Single Session}

${ }^{1}$ Özgür ÖZKAYA
${ }^{1}$ Görkem Aybars BALCI
${ }^{2}$ Hakan AS
${ }^{3}$ Refik ÇABUK
${ }^{2}$ Mahdi NOROUZI

${ }^{2}$ Mahdi NOROUZi

${ }^{1}$ Ege Üniversitesi, Spor Bilimleri Fakültesi

${ }^{2}$ Ege Üniversitesi, Sağlık Bilimleri Fakültesi

${ }^{3}$ Bayburt Üniversitesi Beden Eğitimi ve Spor Yüksek Okulu

\section{Yazışma Adresi \\ Corresponding Address:}

Doç. Dr. Özgür Özkaya

ORCID: 0000-0003-4222-5761

Ege Üniversitesi, Spor Bilimleri Fakültesi, Hareket ve Antrenman Bilimleri Anabilim Dalı

E-posta: ozgur.ozkaya@ege.edu.tr

\section{öz}

Zirve $\mathrm{O}_{2}$ tüketim düzeyi ( $\dot{V} \mathrm{O}_{2 \text { pik}}$ ) veren en yüksek güç çıktısı (aerobik limit güç; $\left.\mathrm{ALG}\right)$ şiddetli ve aşırı egzersiz alanlarını ayıran önemli bir eşiktir ve sporcularda bireysel bir ALG belirleyebilmek için çok sayıda sabit yüklü tüketici test yapmak gerekmektedir. $\mathrm{Bu}$ çalışmanın amacı; sporcuların ALG'lerini tek bir seansta belirleyebilecek bir yaklaşım önermektir. Araştırmaya iyi antrene 12 bisiklet sporcusu katılmıştır $\left(\dot{V} \mathrm{O}_{2 \text { maks: }}\right.$ : $64,7 \pm 4,2 \mathrm{~mL} \cdot \mathrm{dk}^{-1} \cdot \mathrm{kg}^{-1}$; Zirve Güç (ZG): $\left.374,1 \pm 65,7 \mathrm{~W}\right) . \dot{V} \mathrm{O}_{2 \text { pik }}$ düzeyinin belirlenmesi için lineer yük artışlı (ramp) testler uygulatılmıştır $\left(+1 \mathrm{~W} \cdot 2 \mathrm{~s}^{-1}\right)$ ve protokollerin sonunda ulaşılan final güç üretim değerleri (FG) ortalama yanıt zamanı (mean response time: MRT) düzeltmesi uygulanmadan (FGMRT) ve uygulanarak (FGMRT)

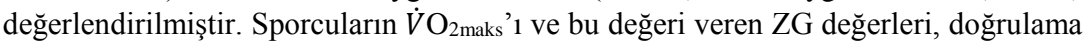

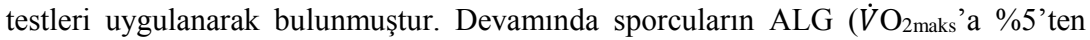
daha yakın $\dot{V} \mathrm{O}_{2}$ değeri veren en yüksek güç çıktısı) değerleri, $15 \mathrm{~W}$ 'lık intervallerle bitkinlikle sonlanan sabit yüklü testler yoluyla ayrı günlerde taranmıştır. FGMRT ile ALG değerleri arasındaki fark anlamlı değildir (FGMRT: 435,2 $\pm 50,8$; ALG: 435,4 $\pm 62,5$ $\mathrm{W}, \mathrm{p}=0,968$ ). Bland-Altman sonuçları yüksek uyum göstermiștir (Bias $=0,20 \pm 17,6 \mathrm{~W}$;

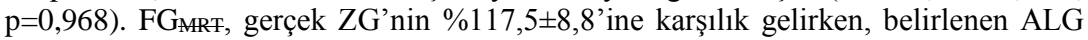
değeri ZG'nin \%117,1 $\pm 7,37$ 'sine karșllık gelmiștir $(\mathrm{p}=0,759)$. Diğer yandan ramp testinden elde edilen en yüksek $15-\mathrm{s} \dot{V} \mathrm{O}_{2}$ ortalamaları da $\mathrm{ALG}$ yükündeki $\dot{V} \mathrm{O}_{2}$ yanitlariyla benzerdir ( Ramp Test: $62,3 \pm 4,9 \mathrm{ml} \cdot \mathrm{dk}^{-1} \cdot \mathrm{kg}^{-1}$, \%96,2; ALG: $61,5 \pm 4,3$ $\left.\mathrm{ml} \cdot \mathrm{dk}^{-1} \cdot \mathrm{kg}^{-1}, \% 95 ; \mathrm{p}=0,119\right)$. Sonuç olarak, ALG'yi belirleyebilmek için ayrı günlerde çok sayıda bitkinlikle sonlanan test yapmak yerine, tek seansta bir ramp test

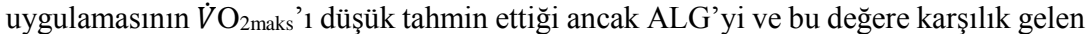
$\dot{V} \mathrm{O}_{2}$ yanıtını belirleyebilmenin oldukça pratik bir yöntemi olabileceği bulunmuştur.

Anahtar Kelimeler: Final güç, Aerobik limit güç, Ramp testi, $\dot{\mathrm{V}} \mathrm{O}_{2 \text { maks, }}, \dot{\mathrm{V}} \mathrm{O}_{2 p i k}$

\section{ABSTRACT}

Although the highest power output to elicit peak $\mathrm{O}_{2}$ consumption $\left(\dot{V} \mathrm{O}_{2 \text { peak }}\right)$ (aerobic limit power; ALP) is an important boundary which separates severe and extreme exercise domain and it needs several constant-load tests to estimate an athlete's individual ALP. The purpose of this study was to suggest an approach to predict the athletes' ALP in a single test session. 12 well-trained cyclists $\left(\dot{V} \mathrm{O}_{2 \max }: 64.7 \pm 4.1\right.$ $\mathrm{mL} \cdot \mathrm{min}^{-1} \cdot \mathrm{kg}^{-1}$ and peak power output (PPO): $374.1 \pm 65.7 \mathrm{~W}$ ) volunteered for this investigation. Ramp incremental test was performed $\left(+1 \mathrm{~W} \cdot 2 \mathrm{~s}^{-1}\right)$ to determine $\dot{V} \mathrm{O}_{2 \text { peak, }}$, and the final power output at the end of the test (FP) was evaluated with and without

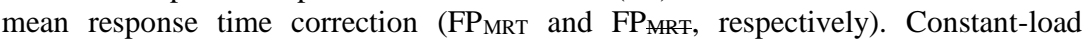
exercises were performed to identify $\dot{V} \mathrm{O}_{2 \max }$ and PPO. Then, athletes' ALP (the highest power output giving a $\dot{V} \mathrm{O}_{2}$ value closer to $\dot{V} \mathrm{O}_{2 \max }$ more than $5 \%$ ) levels were detected by $15-\mathrm{W}$ intervals with constant-load exercises in separate days. Difference between $\mathrm{FP}_{\mathrm{MRT}}$ and ALP was not significant $(435.2 \pm 50.8$ vs. $435.4 \pm 62.5 \mathrm{~W}, \mathrm{p}=0.968$, respectively). Bland Altman showed high agreement between the methods (Bias=$0,20 \pm 17,6 \mathrm{~W} ; \mathrm{p}=0.968)$. FP $\mathrm{ART}$ was corresponded to $117.7 \pm 8.8 \%$ of PPO, while ALP was corresponded to $117.1 \pm 7.37 \%$ of PPO ( $\mathrm{p}=0.00$ ). The highest $15-\mathrm{s} \dot{V} \mathrm{O}_{2}$ means revealed from ramp incremental test were similar to $\dot{V} \mathrm{O}_{2}$ responses obtained from the ALP $\left(62.3 \pm 4.9\right.$ vs. $61.5 \pm 4.3 \mathrm{~mL} \cdot \mathrm{min}^{-1} \cdot \mathrm{kg}^{-1} ; \mathrm{p}=0.119$; and $96.2 \%$ vs. $95 \% \dot{V} \mathrm{O}_{2 \max }$, respectively). In conclusion, instead of several exhausted test sessions in separate days, a ramp incremental test which underestimates the $\dot{V} \mathrm{O}_{2 \max }$ may be a practical method to predict the ALP and its $\dot{V} \mathrm{O}_{2}$ response in a single test session by a ramp incremental test.

Key Words: Final power, Aerobic limit power, Ramp test, $\dot{\mathrm{V}} \mathrm{O}_{2 \max }, \dot{\mathrm{V}} \mathrm{O}_{2 \text { peak }}$ 


\section{GíRIŞ}

Şiddetli (severe) egzersiz alanı, maksimal oksijen kullanımı $\left(\dot{V} \mathrm{O}_{2 \text { maks }}\right)$ ile karakterizedir (Jones ve diğ., 2010). Şiddetli egzersiz alanının alt ve üst eşikleri arasındaki egzersiz şiddetlerinde efor zirve oksijen kullanımı $\left(\dot{V} \mathrm{O}_{2 \text { pik }}\right)$ değerlerinde sonlanır. $\dot{V} \mathrm{O}_{2 \text { pik }}$ değeri, gerçek $\dot{V} \mathrm{O}_{2 \text { maks }}$ 'a $\% 5$ kadar yakın kalınabilen $\dot{V} \mathrm{O}_{2}$ yanıtları anlamına gelir $\left(>\% 95 \dot{V} \mathrm{O}_{2 \text { maks }} \approx \dot{V} \mathrm{O}_{2 \text { pik }}\right)$ ve bu kriter daha önceleri egzersizler süresince $\dot{V} \mathrm{O}_{2 \text { maks }}$ 'ta geçirilen toplam zamanın hesaplandığı önemli çalışmalarda kullanılmıştır (Billat ve diğ., 2000; Black ve diğ., 2015; Buchheit ve Laursen, 2013; de Aguilar ve diğ., 2013; Dupont ve diğ., 2002; Hill ve diğ., 1997; Wakefield ve Glaister, 2009).

Şiddetli egzersizlerin üst sınırı, bitkinliğe kadar $\dot{V} \mathrm{O}_{2 \text { pik }}$ değeri veren en yüksek egzersiz şiddeti olarak tanımlanır (de Aguiar ve diğ., 2013). Bu sınır değer bir miktar aşıldığında ulaşılan güç çıktısıyla sürdürülen egzersizlerde efor süreleri oldukça kısalır ve artan glikolitik katkıya bağlı olarak egzersize $\dot{V} \mathrm{O}_{2}$ yanıtları $\dot{V} \mathrm{O}_{2 \text { pik }}$ 'e ulaşamadan efor bitkinlikle sonlanır (Gaesser ve Poole, 1996; Hill ve diğ., 2002, Hill ve Steven, 2005). Şiddetli egzersizlerin üst sınırı aşıldığında yapılan aşırı (extreme) egzersizlerde bitkinlik süreleri iki dakikanın altına düşer (de Aguiar ve diğ., 2013). İki dakika dolaylarında bitkinlikle sonlanan bir egzersize aerobik ve anaerobik enerji sistemlerinin katkı oranlarının yarı yarıya (\%50:50) olduğu rapor edilmiş̧tir (Åstrand ve Rodahl, 1977). Dolayısıyla bu eşik, toplam enerji üretimine katkının daha yüksek oranda aerobik yollardan temin edilebildiği (\%50+) en yüksek egzersiz şiddeti anlamına gelen aerobik limit gü̧̧ (ALG) olarak ifade edilebilir. ALG hem aerobik güç hem de anaerobik dayanıklıllğa etkili oldukça önemli bir antrenman kriteri sunabilir (Turnes ve diğ,.2016a). Çünkü bu iş yükü egzersize anaerobik katkı oranı oldukça yüksekken halen $\dot{V} \mathrm{O}_{2 p i k}$ yanıtları almaya yetecek kadar uzun bir yüklenme süresi sağlayabilen önemli bir egzersiz şiddetidir.

Diğer yandan ALG, belirlemesi oldukça zahmetli ve birden çok sayıda tüketici test seansı gerektiren bir eşik türüdür ( Hill ve diğ, 2002; Turnes ve diğ. 2016a; Raimundo ve diğ., 2018, Caputo ve Denadai, 2008). Örneğin Hill ve arkadaşlar1 (2002) 3-5 tüketici teste ait güç ve zaman verilerini lineer olmayan 2-parametreli modele fit etmek suretiyle, şiddetli egzersiz alanının üst sınırını tahmin edebilen bir yöntem önermiştir. Caputo ve arkadaşları (2008) ise kademeli bir egzersiz testini takiben 4-6 sabit yüklü tüketici egzersizden elde edilen verilere dayalı bir takım çıkarımların yapıldığı bir yöntem ortaya atmışlardır. Ancak bu yöntemler hem ALG için dolaylı tahminler içermekte hem de yine çok sayıda tüketici test seans1 gerektirmektedir.

Hâlbuki uzun yıllardır gerçek $\dot{V} \mathrm{O}_{2 \text { maks }}$ '1 belirlemede yetersiz görülen ve pek de tercih edilmeyen bir test türü olan doğrusal yük artışlı ramp testler, tek bir seansta ALG'yi verebilir. Çünkü sonlanan ramp tipi kademeli testlerin sonunda

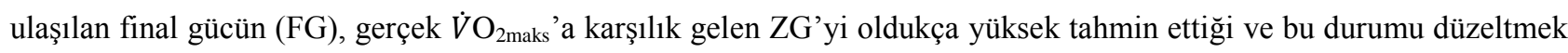
için mean response time (MRT) yani "ortalama yanıt zamanı" anlamına gelen bir düzeltme yapılması gerektiği bildirilmiştir (Boone ve diğ., 2008). Bu uygulamayla ramp test sonunda ulaşılan FG'nin MRT uygulanan ( $\mathrm{FG}_{\mathrm{MRT}}$ ) ve uygulanmayan ( $\mathrm{FG}_{\mathrm{MRT}}$ ) değerleri arasında yaklaşık 20-40W'l1k bir fark oluştuğu ve bu farkın hesaplanan $\mathrm{FG}_{\mathrm{MRT}}$ 'yi ZG'ye denk getirdiği iddia edilmiştir (Boone ve diğ., 2008). Ancak MRT uygulanmayan ham veriler kullanıldığında ulaşılan $F_{\text {MARF }}$ ile $A L G$ arasındaki ilişki daha önce hiç değerlendirilmemiştir. $B u$ çalışma $F G_{\text {MRF }}$ ile ALG güç çıktıları ve bu uygulamalardan elde edilen $\dot{V} \mathrm{O}_{2}$ yanıtları arasındaki farkların anlamlı olup olmadığına odaklanmıştır. 


\section{YÖNTEM}

Araştırma Grubu: Çalışmanın etik kurul izni Ege Üniversitesi, Tıp Fakültesi, Klinik Araştırmalar Etik Kurulundan "ilaç dışı araştırmalar" etik kurul onayı ile alınmıştır (Etik No: 19-1T/40; Proje No: 17.BESYO.002). Çalışmaya

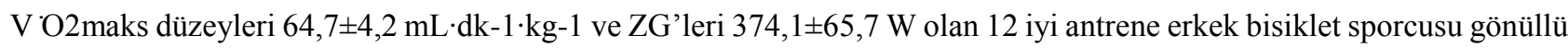

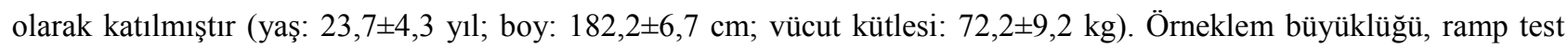
protokolleri değerlendiren önceki araştırmalara dayanarak belirlenmiştir (Leo ve diğ., 2017). Tüm katılımcılar gönüllü olur formunu imzalamışlardır. Ölçümler iklimlendirme laboratuvarında, $\sim 20^{\circ} \mathrm{C}$ sıcaklık, $\% 50-55$ bağıl nem, $>20,7 \% \mathrm{O} 2$, $<500$ ppm CO2 ile karakterize standart iklim koşullarında gerçekleştirilmiştir.

Veri Toplama Araçları: Gönüllülerin boy ve vücut kütlesi ölçümleri, laboratuvar tipi Seca marka bir boy ve vücut kütlesi ölçerle yapılmıştır (Seca 217, Birmingham, UK). Testler sırasındaki kalp atım sayısı takipleri telemetrik yolla veri aktaran sistemlerle kayıt altına alınmıştır (Polar RS 400, Polar Electro Oy, Kempele, Finlandiya). Bisiklet ergometresi olarak elektromanyetik dirençli bir bisiklet ergometresi olan Lode Excalibur Sport kullanılmıştır (Lode Excalibur Sport, Groningen, Netherlands). Gaz değişimleri solunum gazlarını nefesten nefese ölçebilen standart bir sistem kullanılarak değerlendirilmiştir (Innocor, Inno-500, Odense, Denmark).

Deneysel Tasarım: Bu çalışma ileriye dönük tekrarlanan ölçümler deney tasarımına sahip ve deney koşullarının standardize edildiği kontrollü bir laboratuvar çalışmasıdır. Adaptasyon protokollerinin ardından sporcular, şiddetin doğrusal olarak arttırıldığı ramp testlere alınmıştır. Akabinde sporcuların doğrulanmış $\dot{V} \mathrm{O}_{2 \text { maks }}$ düzeyleri, farklı günlerde uygulanan sabit yüklü tüketici testlerle bulunmuştur. Yine sabit yüklü tüketici test protokollerine devam edilerek, sporcuların $\dot{V} \mathrm{O}_{2 \text { maks }}$ düzeylerine $\% 5$ kadar yakın kalabildikleri en yüksek güç üretim düzeyleri tespit edilmiştir. ALG yükü ve bu iş oranında kullanılabilen en iyi 15 -s ortalamasına ait $\dot{V} \mathrm{O}_{2}$ düzeyleri ile ramp testler sonunda ulaşılan $\mathrm{FG}_{\mathrm{MRT}}$ ve $\mathrm{FG}_{\mathrm{MRT}}$ değerleriyle elde edilen en iyi 15 -s ortalamasına ait $\dot{V} \mathrm{O}_{2}$ düzeyleri analitik yöntemler kullanılarak değerlendirilmiş̧tir. $\mathrm{Bu}$ analizlerde ramp testin sonunda ulaşılan $\dot{V} \mathrm{O}_{2}$ düzeyleri ve $\mathrm{FG}_{\mathrm{MRT}}$ 'nin ALG'yi temsil edip edemeyeceğine ait varsayımlar sınanmıştır.

Verilerin Toplanması: Sporcular egzersiz şiddetinin doğrusal olarak arttırıldığı ramp testlere adepte edilmiştir. Bu adaptasyon çalışmalarında yükün aerobik eşik dolaylarından (kalp atım sayısı rezervinin \%50'si) tahmini anaerobik eşiğe (kalp atım sayısı rezervinin \%70'i) kadar arttırıldığı protokoller kullanılarak sporcuların ilk adaptasyonları sağlanmıştır. Devamında her sporcu en az birer kez olmak üzere bu protokolleri bitkinliğe kadar uygulamıştır. Söz konusu protokollerin yük artırımlarında orta hızlı yük artışı $\left(1-\mathrm{W} \cdot 2 \mathrm{~s}^{-1}\right)$ esas alınmıştır. Adaptasyon çalışmalarından elde edilen veriler, esas çalışmaya dâhil edilmemiştir.

Çalışmaların esas evresinde kademeli ramp testlerine adaptasyon sağlamış sporcular testlere alınmıştır. Bu testlerin yük artırımları başlamadan önce sporculardan 4 dakika süresince $70 \pm 10 \mathrm{rpm}$ dolaylarında yüksüz pedal çevirmeleri istenmiştir. 4 dakikalık periyodun sonunda bisiklet elektromanyetik yollarla frenlenerek, $1-\mathrm{W} \cdot 2 \mathrm{~s}^{-1}$ yük $\operatorname{artış1~}$ uygulanmıştır. Yük artışları sporcunun istemli bitkinliğine kadar aynı esaslarla sürdürülmüştür ve anaerobik eşik geçildikten sonra sporculardan $90 \pm 10 \mathrm{rpm}$ pedal çevrim hızlarına çıkmaları istenmiştir. Kademeli ramp testlerinde anaerobik eşik dolayları $\mathrm{VCO}_{2}-\mathrm{VO}_{2}$ ikili regresyonundaki kırılma ( $v$-slope) esas alınarak değerlendirilmiştir. Solunumsal anaerobik eşik aşıldığında sporculara verilen sözel motivasyon desteği güçlendirilerek bitkinliğe kadar sürdürülmüştür. Kademeli testler, sporcuların pedal çevrim hızları 10 saniyeden uzun süre $80 \mathrm{rpm}$ ve altına düşüldüğünde sonlandırılmışıtır. Testler sırasında her dakikanın sonunda sporcuların algıladıkları zorluk (rating of perceived exertion: 
RPE) sorgulanmıştır. Testin doğruluğu, test sonunda sporculardan alınan maksimal kalp atım sayısı yanıtı (220-yaş’a \%10'dan daha yakın değer), $\geq 1,05$ solunum değişim katsayısı (respiratory exchange ratio: RER) yanıtı ve RPE'de $\geq 19$ ile değerlendirilmiştir. Kriterlere uymayan testler, devam eden günlerde tekrarlanmıştır. Ramp testlerde ulaşılan güç çıktısının ZG’yi yüksek tahmin ettiği bilindiğinden, ramp sonuçlarına MRT uygulanmıştır (Boone ve diğ., 2008). Bu uygulamalarda egzersiz başından anaerobik eşik düzeyine kadar alınan $\mathrm{VO}_{2}$ yanıtları 15-s ortalamalar şeklinde kullanılmıştır. Sonrasında $\mathrm{VO}_{2}$ 'ye göre zamana ait regresyon ilişkisi $y=a \cdot x+b$ olarak hesaplanmıştır. MRT hesaplamalarında paraziti azaltabilmek için zamana göre fonksiyon olarak ifade edilecek $\mathrm{VO}_{2}$ verilerinin ilk üç dakikasına ait veriler regresyondan çıkarılmıştır (Leo ve diğ., 2017). Bu analiz $\mathrm{VO}_{2}$ 'de doğrusal trendin oluşmasıyla kontrol edilmiştir. Elde edilen veri, yüksüz pedal çevrimi sırasında harcanan $\mathrm{VO}_{2}$ düzeyine kadar doğrusal regresyon modelinde geri-ekstrapolasyon uygulanarak çizdirilmiştir. Bu kesişimin zaman eksenindeki iz düşümünden MRT değeri hesaplanmıştır. $\mathrm{VO}_{2}$ düzeyine karşılık gelen yükler, hesaplanan MRT zamanı kadar ileri alınarak, üretilen güç çıktısına kıyasla $\mathrm{VO}_{2}$ yanıtlarında oluşan gecikme düzeltilmiştir.

Kademeli testlerin ardından sporcular bir günlük aralıklarla sabit yüklü tüketici doğrulama testlerine alınmıştır. Bu doğrulama testlerine $\mathrm{FG}_{\text {MRT }}$ yükünden başlanarak $\pm 15-\mathrm{W}$ aralıklarla taramalar yapılmıştır. Sabit yüklü tüketici testlerde sporculardan $90 \pm 10 \mathrm{rpm}$ aralığında kalmaları istenmiştir. Sporcuların pedal çevrim hızları 10 saniyeden uzun süre 80 rpm ve altına düştüğünde protokoller sonlandırılmıştır. Tüm testlerde sporculara güçlü sözel motivasyon desteği verilmiştir. Sabit yüklü taramalarda testin doğruluğu, test sonunda sporculardan alınan maksimal kalp atım sayısı yanıtı (220-yaş’a \%10'dan daha yakın değer), $\geq 1,05$ RER yanıtı ve RPE'de $\geq 19$ ile değerlendirilmiştir. Bulunan en yüksek 15 s $\mathrm{VO}_{2}$ ortalaması, $\dot{V} \mathrm{O}_{2 \text { maks }}$ olarak kaydedilmiştir.

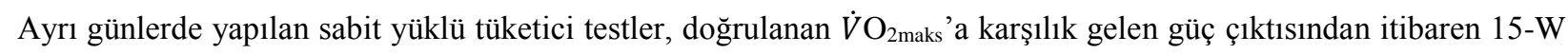
artışlarla sürdürülmüştür. Çalışmanın bu kısmında her sporcuya ait bireysel bir ALG ve bu düzeye karşılık gelen en yüksek 15-s $\mathrm{VO}_{2}$ ortalaması belirlenmiştir. Sporcuların bireysel ALG düzeyleri, yük artışına rağmen halen $\dot{V} \mathrm{O}_{2 \text { maks'a }}$ \%5’ten daha yakın $\dot{V} \mathrm{O}_{2}$ yanıtı $\left(\dot{V} \mathrm{O}_{2 \text { pik }}\right)$ alınabilen en yüksek güç çıktısı olarak kabul edilmiştir. Tüm testlerde sporculara güçlü sözel motivasyon desteği verilmiştir. Çalışmanın bu kısmında esas alınan rpm ve test sonlandırma usulleri bir önceki aşamada benimsenenlerle aynıdır..

Verilerin Analizi: Sonuçlar geleneksel bir veri analiz programı olan SPSS (SPSS 21, SPSS Inc., Chicago, USA) ve Microsoft Excel (Excel 2010, Microsoft, Redmond, USA) kullanılarak değerlendirilmiştir. Basıklık ve çarpıklık analizlerinin ardından, ortalama değerler arasındaki farklar tekrarlanan ölçümler ANOVA ve ikili karşılaştırmalar LSD

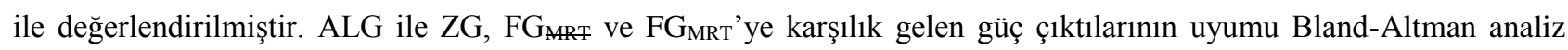
yöntemiyle değerlendirilmiştir (Atkinson ve Nevill, 1998; Bland ve Altman, 1986). Bland-Altman analizlerinden elde edilen ortalama farkların (Bias) sıfırdan farklı olup olmadığı, tek örneklem t-testi ile belirlenmiştir. İstatistiksel analizlerde anlamlılık düzeyi $\mathrm{p}<0,05$ olarak kabul edilmiştir.

\section{BULGULAR}

$\mathrm{FG}_{\text {MRRT }}$ ve $\mathrm{FG}_{\mathrm{MRT}}$ farkı 25,6 24,6 W'dır (p=0.00). Buna rağmen halen $\mathrm{FG}_{\mathrm{MRT}}$ değeri gerçek $\dot{V} \mathrm{O}_{2 \text { maks }}$ 'a karşılık gelen ZG'den 36,5 W kadar yüksektir ( $\mathrm{p}=0.00$ ) (Tablo 1). Elde edilen bulgulara göre, FG $\mathrm{F}_{\text {MRT }}$ ile ALG değerleri arasındaki fark anlamlı değildir $(\mathrm{p}=0,968)$. Bland-Altman sonuçları da bu durumu doğrulayarak yüksek uyum göstermiştir (Bias=0,20 $\pm 17,6 \mathrm{~W} ; \mathrm{p}=0,968)$ (Tablo 2 ve Şekil 1). 
Tablo 1. Kademeli ramp ve sabit yüklü testlerin watt ortalamalarının post-hoc analizleri

\begin{tabular}{|c|c|c|}
\hline Değişkenler & Güç \pm SS (W) & Post-hoc \\
\hline ALG & $435,4 \pm 62,5$ & $=\mathrm{FG}_{\mathrm{MRT}},>\mathrm{FG}_{\mathrm{MRT}} *, \mathrm{ZG}^{*}$ \\
\hline FG $_{\text {MRT }}$ & $435,2 \pm 50,8$ & $=\mathrm{ALG},>\mathrm{FG}_{\mathrm{MRT}} *, \mathrm{ZG}^{*}$ \\
\hline FG $_{\text {MRT }}$ & $410,6 \pm 51,1$ & $<\mathrm{ALG}^{*}, \mathrm{FG}_{\mathrm{ART}}{ }^{*},>\mathrm{ZG}^{*}$ \\
\hline $\mathbf{Z G}$ & $374,1 \pm 65,7$ & $<\mathrm{ALG}^{*}, \mathrm{FG}_{\mathrm{MRT}}{ }^{*}, \mathrm{FG}_{\mathrm{MRT}}$ \\
\hline
\end{tabular}

ALG= Aerobik Limit Güç; FGMRT= MRT'siz Final Güç; FGMRT; MRT’li Final Güç; ZG= Zirve Güç; * p<0,05

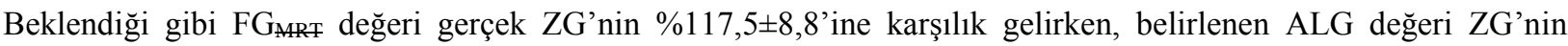

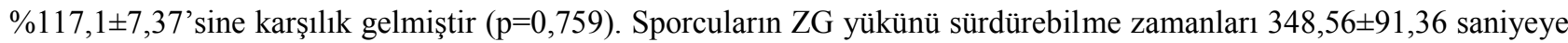

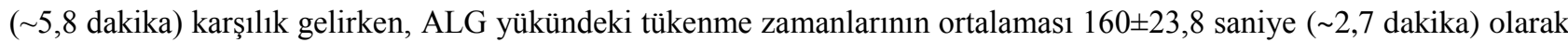
bulunmuştur.

Diğer yandan kademeli ramp testlerden elde edilen en yüksek 15-s $\dot{V} \mathrm{O}_{2}$ ortalamaları da ALG yükündeki 15-s ortalamalarla benzerdir $(\mathrm{p}=0,119)$. Saptanan $\dot{V} \mathrm{O}_{2}$ farkı grup ortalaması adına yalnızca $0,8 \mathrm{~mL} \cdot \mathrm{dk}^{-1} \cdot \mathrm{kg}^{-1} \mathrm{olmuştur}$.

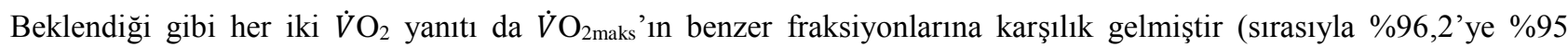
$\dot{V} \mathrm{O}_{2 \text { maks }}$ ). Ancak her iki $\dot{V} \mathrm{O}_{2}$ ortalaması da gerçek $\dot{V} \mathrm{O}_{2 \text { maks }}$ 'tan yaklaşı $-3 \mathrm{~mL} \cdot \mathrm{dk}^{-1} \cdot \mathrm{kg}^{-1}$ daha düşüktür $(\mathrm{p}=0,00)(\mathrm{Tablo} 3)$.

Tablo 2. Aerobik limit güç ile kademeli ramp testten elde edilen MRT'li ve MRT'siz güç çıktılarının ortalama watt, ortalama fark ve uyum sınırları

\begin{tabular}{lcc}
\hline Değişkenler & FG $_{\text {MART }} \pm$ SS & FG $_{\text {MRT }} \pm$ SS \\
\hline Güç Çıktısı (W) & $435,3 \pm 56,2$ & $423,0 \pm 56,4$ \\
Ortalama Fark (W) & $0,20 \pm 17,6$ & $24,8 \pm 17,9^{*}$ \\
Uyum Sınırları (W) & $-34,3$ ile 34,7 & $-10,31$ ile 59,9 \\
\hline
\end{tabular}

$\mathrm{FG}_{\mathrm{MRT}}=$ Final güç üretim değerlerinin ortalama yanıt zamanı düzeltmesi uygulanmadan ulaşılan değer; $F_{\text {FMRT }}=$ Final güç üretim değerlerinin ortalama yanıt zamanı düzeltmesi uygulayarak ulaşılan değer; *Ortalama farklar sıfir (0)'dan anlamlı düzeyde farklı; * $\mathrm{p}<0,05$

Tablo 3. Kademeli ramp ve sabit yüklü testlerin $\dot{V} \mathrm{O}_{2}$ ortalamalarının post-hoc analizleri

\begin{tabular}{|c|c|c|}
\hline Değişkenler & $\dot{V} \mathrm{O}_{2} \pm \mathrm{SS}\left(\mathrm{mL} \cdot \mathrm{min}^{-1} \cdot \mathrm{kg}^{-1}\right)$ & Post-hoc \\
\hline ALG & $61,5 \pm 4,3$ & $=$ Ramp- $\dot{V} \mathrm{O} 2_{\text {pik, }}<\mathrm{ZG}^{*}$ \\
\hline Ramp- $\dot{V} \mathbf{O}_{2 \text { pik }}$ & $62,3 \pm 4,9$ & $=\mathrm{LG},<\mathrm{ZG}^{*}$ \\
\hline ZG & $64,7 \pm 4,2$ & $>\mathrm{LG}^{*}, \mathrm{Ramp}-\dot{V} \mathrm{O} 2_{\mathrm{pik}}{ }^{*}$ \\
\hline
\end{tabular}

$\mathrm{ALG}=$ Aerobik Limit Güç; Ramp- $\dot{V} \mathrm{O}_{2 p i k}=$ Ramp testten elde edilen en yüksek güç üretimi; $\mathrm{ZG}=$ Zirve Güç; * $p<0,05$ 


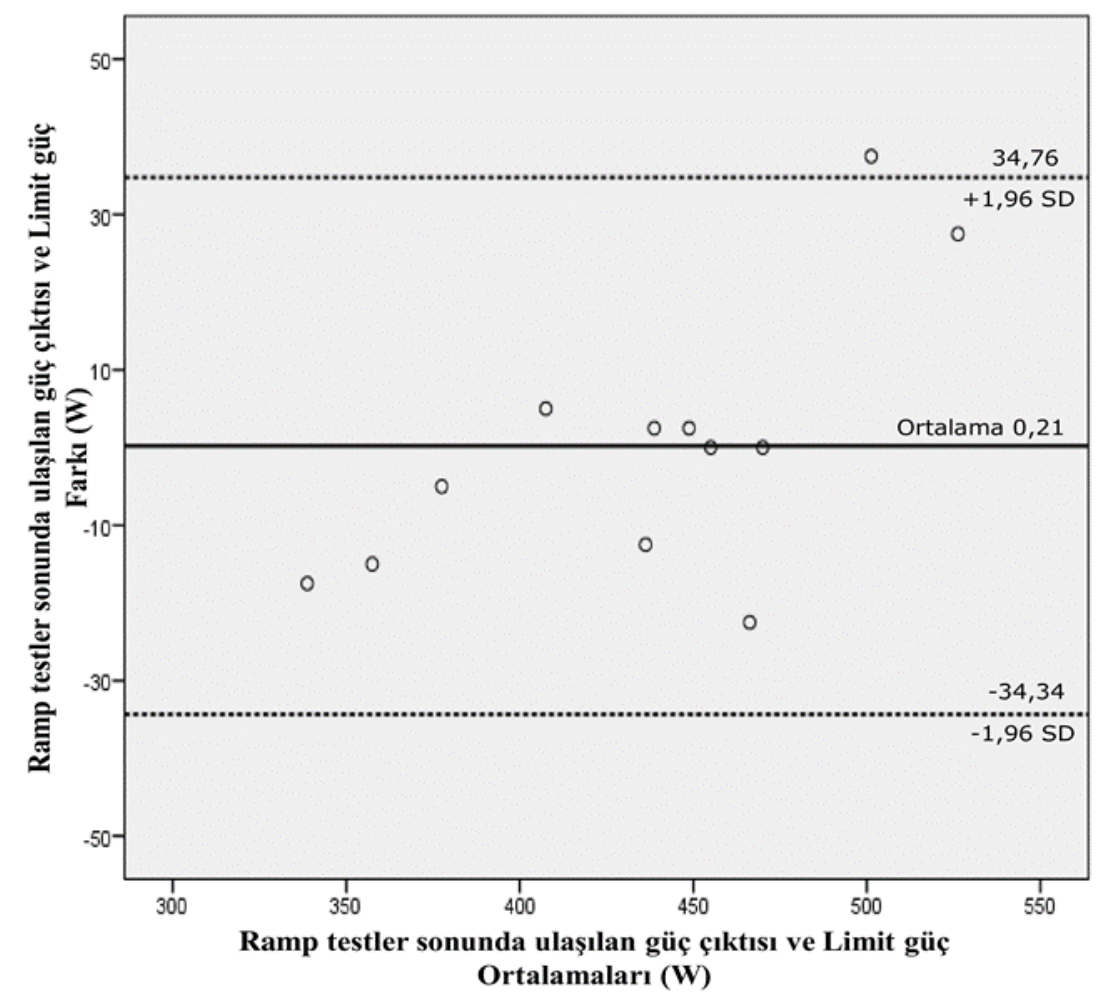

Şekil 1. Ramp testler sonunda ulaşılan güç çıktıları ve aerobik limit güç uyumunu gösteren Bland-Altman grafiği

\section{TARTIŞMA}

$\mathrm{Bu}$ çalışmanın ana bulguları; tek bir seansta ve yalnızca bir tükenme ile uygulanabilen ramp testi sonunda ulaşılan final güç üretim düzeyinin MRT uygulanmamış sonuçlarının ( $\mathrm{FG}_{\mathrm{MARF}}$ ) ALG'e karşılık gelen güç üretim düzeyini (435,2'ye kıyasla 435,4 W; p=0,96) ve ramp testi sırasında ulaşılan en yüksek 15-s $\dot{V} \mathrm{O}_{2}$ ortalamasının ise ALG egzersizlerinde ulaşılan $\dot{V} \mathrm{O}_{2}$ yanıtını $\left(62,3\right.$ 'e kıyasla $\left.61,5 \mathrm{~mL} \cdot \mathrm{dk}^{-1} \cdot \mathrm{kg}^{-1} ; \mathrm{p}=0,119\right)$ verdiğini göstermiştir. Bu sayede belirlemesi oldukça meşakkatli bir eşik değer olan ALG, tek bir seansta ve tek bir tükenme ile belirlenmiştir.

Günümüzde ALG, performans ölçümlerinde sıklıkla belirlenen ve üzerinde durulan önemli bir eşik değer değildir. Aerobik eşik (örneğin laktat eşiği, $\mathrm{VCO}_{2}-\mathrm{VO}_{2}$ ikili regresyonundaki ilk kırılma, vb.), anaerobik eşik (maksimal laktat dengesi, $\mathrm{VCO}_{2}-\mathrm{VO}_{2}$ ikili regresyonundaki ikinci kırılma, vb.) ve aerobik güce $\left(\dot{V} \mathrm{O}_{2 \text { maks }}\right)$ kıyasla $\mathrm{ALG}$, bireysel olarak belirlenen ve antrenmanlar sırasında egzersiz yükünün dikkate alınarak değerlendirildiği bir eşik olarak dikkate alınmamaktadır. Ancak ALG'de yapılan egzersizler hem aerobik güç hem de anaerobik kapasite geliştirmede oldukça etkili egzersiz uyaranı doğurabilir. Çünkü ALG, sporcuların tek bir yüklenmede glikolitik yollardan hatırı sayılır oranda enerji elde etmelerine yetecek kadar yüksek bir egzersiz şiddeti barındırırken, diğer yandan her bir yüklenmede 15 ya da 30'ar saniyelik ortalama $\dot{V} \mathrm{O}_{2}$ yanıtlarının $\dot{V} \mathrm{O}_{2 \text { pik' }}$ 'e ulaşmasına imkân tanıyacak ölçüde düşük bir egzersiz şiddetidir. Ancak ALG ile ilgili çalışma sayısı oldukça sınırlıdır. ALG'de egzersiz etkilerinin araştırıldığı yalnızca bir önemli çalışmaya ulaşılabilmiştir. Turnes ve arkadaşları (2016b) yaptıkları çalışmada; matematiksel modellemelerle elde edilen kritik gücün $(\mathrm{KG}) \% 105$ 'inde (şiddetli egzersiz alanının alt sınırlarında) $4 \times 5$ dakikalık yüklenmeler ve 1:0,2 yüklenme/dinlenme oranlarına kıyasla ALG'de (şiddetli egzersiz alanının üst sınırlarında) $8 \times \dot{V} \mathrm{O}_{2 \text { pik }}$ 'te geçirilen zamanın \%60’ı kadar yüklenme süresi ve 1:2 yüklenme/dinlenme oranına sahip iki antrenman modelinden elde edilen yanıtları 
karşılaştırmışlardır. Elde edilen bulgular, her iki yükte de benzer aerobik dayanıklılık geliştirici etkiler görüldüğünü işaret etmiş̧ir.

ALG'yi doğru belirleyebilmek oldukça önemlidir (Hill ve diğ, 2002; Turnes ve diğ,. 2016a; Raimundo ve diğ., 2018, Caputo ve Denadai, 2008). Farklı usullere dayalı olarak ALG belirlemede kullanılabilecek iki önemli uygulama önerilmiştir. Hill ve arkadaşları (2002) 3-5 tüketici teste ait güç ve zaman verilerini lineer olmayan 2-parametreli modele fit ederek ALG belirleyebilecek bir yöntem önermiştir. Bu yönteme göre tüketici testlerden elde edilen tükenme süreleri ve egzersiz şiddetlerine ait hiperbolik ilişki ile aynı testlere ait $\dot{V} \mathrm{O}_{2 \text { maks }}$ 'ta geçirilen zaman verileri üst üste çizdirildiğinde oluşan ikinci ilişkinin x-ekseni kavuşmazı dolaylarındaki kesişim noktası ALG'deki tükenme zamanını vermektedir. $\dot{V} \mathrm{O}_{2 \text { maks }}$ 'da geçirilen zaman ve tükenme zamanlarına ait lineer ilişkiyi $45^{\circ}$ 'lik izdüşümünün kesişimi ise bu zamanı doğrulamaktadır. Bir diğer ALG belirleme yöntemi ise Caputo ve arkadaşları (2008) tarafından önerilmiştir. Bu yöntemde kademeli bir egzersiz testini takiben 4-6 adet sabit yüklü tüketici egzersizden elde edilen verilere dayalı birtakım çıkarımlar yapılmıştır. Burada sabit yüklü testler ve kademeli testlerden elde edilen en yüksek $\dot{V} \mathrm{O}_{2}$ değerinin standart sapması, $\dot{V} \mathrm{O}_{2 \text { maks }}$ 'tan ne oranda uzaklaşılacağının anlaşılmasında en önemli belirleyici olarak kullanılmıştır. Ancak önerilen tüm yöntemler çok sayıda tüketici test ve egzersiz seansı gerektirmektedir. Yaptığımız çalışmada elde edilen bulgular, dakikada $30 \mathrm{~W}$ 'lık orta hızlı kademe artışları içeren standart bir ramp testin sonunda ulaşılan güç çıktısı değerlerinin zaten ALG dolaylarında sonlandığını ve bu düzeyin de doğrulanmış ZG’nin \%17 üzerindeki egzersiz şiddetlerini verdiğini gösterdi.

Yaptığımız çalışmada öne çıkan bulgulardan bir diğeri de, MRT uygulanmadan esas alınan ramp test sonuçlarının gerçek $\dot{V} \mathrm{O}_{2 \text { maks }}$ ve bu değere karşılık gelen ZG'yi göstermedeki başarısızlığıdır. Gerçekten de MRT uygulanmadan esas alınan ramp testi sonuçları gerçek $\dot{V} \mathrm{O}_{\text {2maks }}$ 'n hatırı sayılır düzeyde altında ve gerçek ZG'nin ise önemli bir miktarda üzerindeki güç üretim seviyelerini göstermiştir. Standart bir ramp testi uygulamasında sporcuların tükenene kadar geçen zamanda ZG'nin üzerindeki güç üretim seviyelerinde bile testi devam ettirebilmelerinin en önemli nedeni, protokoller sırasında hızlıca artan egzersiz şiddeti nedeniyle uygulanan yüklere maruz kalınan ortalama zamanların düşük olması ve bu nedenle ilgili yüklere alınan fizyolojik yanıtların gecikmesidir. MRT uygulamaları tam da bu nedenle önerilmiştir (Boone ve diğ., 2008). Bu uygulamalar yoluyla, ramp testler sonunda ulaşılan güç üretim düzeyleri standart bir uygulamada yaklaşık $20-40 \mathrm{~W}$ aşağıya çekilerek hata düzeltilir. Bu çalışmada hesaplanan MRT düzeltmesi $\sim 25 \mathrm{~W}$ kadardır.

Standart bir ramp uygulamasının özellikle elit olmayan dayanıklılık sporcularında gerçek $\dot{V} \mathrm{O}_{2 \text { maks }}$ '1 açığa çıkaramadığı ve bu değerin altında bir $\dot{V} \mathrm{O}_{2}$ yanıtına neden olacak şekilde bir tükenme gerçekleştĭgi bilinir. Bunun en önemli nedeni ise, yükselen iç sıcaklığa bağlı olarak artan deri kan akışının kalbe geri dönen kan hacmini önemli düzeyde düşürmesi ve buna bağlı olarak düşen kalp atın hacminin koroner kanlanmayı bozarak kalbi olumsuz etkilemesidir (Lepretre ve diğ., 2004). Bu durumda beyin, iskelet kaslarının koordinasyonunu bozarak kalbi ve tüm sistemi koruma altına almaya çalışır. Dolayısıyla gerçek $\dot{V} \mathrm{O}_{2 \text { maks' }}$ ’n açı̆̆a çıkarılması; kalp kasının, iskelet kasları en yüksek arteriovenöz $\mathrm{O}_{2}$ farkına ulaşmadan ve maksimal kalp atım sayısı yakalanmadan önce yorulmayacağı koşulların sağlandığı bir egzersiz protokolüyle açığa çıkarılabilir. Bu durumda $\dot{V} \mathrm{O}_{2 \text { maks }}$ '1 belirlemede en doğru yaklaşım, genellikle 3-5 dakikada bitkinlikle sonlanacak sabit yüklü tüketici test uygulamalarıdır (Çolakoğlu ve diğ., 2016). Bu çalışmada ramp testleri sırasında ulaşılabilen en yüksek $\dot{V} \mathrm{O}_{2}$ yanıtlarıyla her sporcu için bireysel olarak belirlenen $\dot{V} \mathrm{O}_{2 \text { maks }}$ arasındaki fark \%4 kadar yüksektir. Dahası günümüze kadar yapılan hiçbir çalışmada $A L G$ değeri, doğrulanmış bir $\dot{V} \mathrm{O}_{2 \text { maks }}$ üzerinden hesaplanmamıştır. Örneğin benzer sorunsal yaklaşımlara dayalı yöntemlerle Raimundo ve arkadaşları (2019) ALG belirlemeye çalışmışlardır. Yazarlar bu çalışmalarında kademeli testlerden elde ettikleri zirve değeri $\dot{V} \mathrm{O}_{2 \text { maks }}$ olarak esas 
almışlar ve sporcuların $\dot{V} \mathrm{O}_{2 \text { maks }}$ 'a ulaşabildikleri en yüksek iş oranını bulana kadar iş yükünü $\% 5$ arttırarak sabit yüklü test protokolleri uygulamışlardır. Ancak bu çalışmada sporcular, önceden $\dot{V} \mathrm{O}_{2 \text { maks }}$ olarak belirlenen değerlerin üzerine çıkmışlar ve ilerleyen safhalarda tekrar $\dot{V} \mathrm{O}_{2 \text { maks }}$ 'a düşerek halen $\dot{V} \mathrm{O}_{2 \text { maks }}$ veren en yüksek egzersiz şiddeti yani ALG seviyelerine ulaşmışlardır. Bu ve benzer çalışmalarda sporcuların önceden "maksimal" olarak belirlenen ortalama değerlerin üzerindeki $\dot{V} \mathrm{O}_{2}$ yanttlarına nasıl ulaşabildikleri ve altta kalan değerlerin nasıl olup da " $\dot{V} \mathrm{O}_{2 \text { maks }}$ " olarak nitelendirilebildiği oldukça büyük bir sorudur. Dolayısıyla çalışmamızdan elde edilen en önemli sonuçlardan biri de, gerçek ALG’yi belirlemenin yolu olmuştur. En doğru şekilde ALG belirlemenin yöntemi, doğrulama testleriyle bir $\dot{V} \mathrm{O}_{2 \text { maks }}$ ve bu değere karşı1lı gelen bir ZG belirledikten sonra, egzersiz şiddetini \%4-5 ya da 15-20 W oranında arttırarak $\dot{V} \mathrm{O}_{2 \text { maks }}$ 'a \%5 kadar uzak kalınabilen en yüksek egzersiz şiddetini sabit yüklü testlerle belirlemektir.

\section{SONUÇ VE ÖNERILER}

Sonuç olarak ALG düzeyi ZG'nin yaklaşı \%117'si dolaylarına karşılık gelmiştir ve bu düzeyde kaydedilen tükenme zamanları yaklaşık 2,7 dakika dolaylarındadır. ALG, tek bir yük kullanarak hem aerobik hem de anaerobik dayanıklılık geliştirmede oldukça önemli bir egzersiz uyaranı olabilir. Dolayısıyla pratik bir şekilde ve doğru tahmin edilmesi oldukça önemlidir. Elde ettiğimiz bulgulara göre, standart bir ramp testi sonunda ulaşılan ve MRT uygulanmayan final güç üretim düzeyi ALG'yi verebilir.

\section{KAYNAKLAR}

1. Åstrand PO, Rodahl K. (1977). Textbook of work physiology: physiological bases of exercise. (2 ${ }^{\text {th }}$ Edition) New York: McGraw-Hill Book Company.

2. Atkinson G, Nevill AM. (1998). Statistical methods for assessing measurement error (reliability) in variables relevant to sports medicine. Sports Medicine, 26(4),217-38.

3. Billat VL, Slawinski J, Bocquet V, Demarle A, Lafitte L, Chassaing P, vd. (2000). Intermittent runs at the velocity associated with maximal oxygen uptake enables subjects to remain at maximal oxygen uptake for a longer time than intense but submaximal runs. European Journal of Applied Physiology, 81(3),188-96.

4. Black MI, Jones AM, Bailey SJ, Vanhatalo A. (2015). Self-pacing increases critical power and improves performance during severeintensity exercise. Applied physiology, nutrition, and metabolism, 40(7),662-70.

5. Bland JM, Altman DG. (1986). Statistical methods for assessing agreement between two methods of clinical measurement. The Lancet, 327(8476),307-10.

6. Boone J, Koppo K, Bouckaert J. (2008). The VO2 response to submaximal ramp cycle exercise: Influence of ramp slope and training status. Respiratory physiology \& neurobiology, 161(3),291-7.

7. Buchheit M, Laursen PB. (2013). High-Intensity interval training, solutions to the programming puzzle. Sports medicine, 43(5),313-38.

8. Caputo F, Denadai BS. (2008). The highest intensity and the shortest duration permitting attainment of maximal oxygen uptake during cycling: effects of different methods and aerobic fitness level. European Journal of Applied Physiology, 103(1),47-57.

9. Colakoglu M, Ozkaya O, Balci GA, Yapicioglu B. (2016). Stroke volume responses may be related to the gap between peak and maximal O2consumption. Isokinetics and Exercise Science, 24(2),133-9.

10. de Aguiar RA, Turnes T, de Oliveira Cruz RS, Caputo F. (2013). Fast-start strategy increases the time spent above $95 \%$ VO2max during severe-intensity intermittent running exercise. European journal of applied physiology, 113(4),941-9.

11. Dupont G, Blondel N, Lensel G, Berthoin S. (2002). Critical velocity and time spent at a high level of VO2 for short intermittent runs at supramaximal velocities. Canadian journal of applied physiology, 27(2),103-15.

12. Gaesser GA, Poole DC. (1996). The slow component of oxygen uptake kinetics in humans. Exercise and sport sciences reviews, 24(1),3571. 
13. Hill D, Williams C, Burg S. (1997). Responses to exercise at $92 \%$ and $100 \%$ of the velocity associated with VO2max. International journal of sports medicine, 18(5),325-9.

14. Hill DW, Poole DC, Smith JC. (2002). The relationship between power and the time to achieve VO2max. Medicine and science in sports and exercise, 34(4),709-14.

15. Hill DW, Stevens EC. (2005). VO2 response profiles in severe intensity exercise. The Journal of sports medicine and physical fitness, 45(3),239-47.

16. Jones AM, Vanhatalo A, Burnley M, Morton RH, Poole DC. (2010). Critical power: implications for determination of VO2max and exercise tolerance. Medicine and science in sports and exercise, 42(10),1876-90.

17. Leo JA, Sabapathy S, Simmonds MJ, Cross TJ. (2017). The respiratory compensation point is not a valid surrogate for critical power. Medicine and science in sports and exercise, 49(7),1452-60.

18. Lepretre P-M, Koralsztein J-P, Billat VL. (2004). Effect of exercise intensity on relationship between VO2max and cardiac output. Medicine and science in sports and exercise, 36(8),1357-63.

19. Raimundo JAG, Turnes T, de Aguiar RA, Lisbôa FD, Loch T, Ribeiro G, vd. (2019). The severe exercise domain amplitude: a comparison between endurance runners and cyclists. Research Quarterly for Exercise and Sport, 90(1),3-13.

20. Turnes T, de Aguiar RA, de Oliveira Cruz RS, Lisbôa FD, Pereira KL, Caputo F. (2016). Short-term interval training at both lower and higher intensities in the severe exercise domain result in improvements in on-kinetics. European Journal of Applied Physiology, $116(10), 1975-84$.

21. Turnes T, de Aguiar R, de Oliveira Cruz R, Pereira K, Salvador A, Caputo F. (2016). High-intensity interval training in the boundaries of the severe domain: effects on sprint and endurance performance. International Journal of Sports Medicine, 37(12),944-51.

22. Wakefield BR, Glaister M. (2009). Influence of work-interval intensity and duration on time spent at a high percentage of VO2max during intermittent supramaximal exercise. Journal of strength and conditioning research, 23(9),2548-54. 